\title{
Histo-Cytochemical Characteristics of Primordial Germ Cells in Human Embryos
}

\author{
By \\ Yukihiko MIYAYAMA, Haruhiko MIYAYAMA* and Toyoaki FUJIMOTO** \\ Department of Midical Technology, Kumamoto University College of Medical Science, Kumamoto 862 (Y.M.), \\ *Department of Pathology (H.M.) and **Anatomy (T.F.), Kumamoto University Medical School, \\ Kumamoto 860, Japan
}

- Received for Publication, January 9, $1984-$

\begin{abstract}
Key Words: Human embryo, Primordial germ cells, Plasma membrane, Histochemical identification, Enzyme activity

Summary: The histo-cytochemical characteristics of primordial germ cells (PGCs) in early human embryos were investigated in conjunction with identification of the cells. Employing the periodic acid-Schiff (PAS) reaction, PGCs in the migration stage or in the early settlement stage were clearly distinguished from somatic cells by their content of PAS-positive intracytoplasmic glycogen. The alkaline phosphatase (ALPase) reaction was confirmed to represent a useful method for identifying PGCs throughout their endodermal to settlement stages. The enzyme activity was detectable on the plasma membrane of PGCs, especially in parts associated with other adjacent cells, and also on the outer membrane of mitochondria, the Golgi apparatus and the nuclear envelope of PGCs. Histochemically, the ALPase of PGCs revealed heat-lability and inhibition by levamisole, suggesting that the isozyme was of the liver type. Using the colloidal iron reaction, acid mucin was demonstrated on the surface of PGC which was alcianophilic. This indicated that the plasma membrane of PGC is composed of acid mucin including sialic acid, and also that this method is applicable to the identification of PGCs.
\end{abstract}

In previous studies on the origin and migration of human primordial germ cells (PGCs) at the ultrastructural level (Fujimoto et al., 1977, Miyayama et al., 1977), we found that the histo-cytochemical alkaline phosphatase (ALPase) reaction as well as the periodic acid-Schiff (PAS) reaction, both of which were introduced by McKay et al. (1953), represented very effective means for identifying PGCs. With the ALPase reaction, enzyme activity was demonstrated selectively on the plasma membrane of the PGC, as in the case of mouse PGCs (Jeon and Kennedy, 1973; etc.). It was strongly suggested in our previous reports that cell organelles such as mitochondria or the Golgi apparatus of human PGCs as well as the plasma membrane, were also reactive to the ALPase reaction. To verify this, and to determine the histochemical characteristics of human PGCs in relation to histochemical identification of the cells, the present study was undertaken on materials from human embryos.

\section{Materials and Methods}

Human embryos obtained by legal abortion were used. They comprised one embryo at the 4 th week of gestation $(22$. somite stage), 6 embryos at the 5 th week

The present study was supported in part by a Grant-in-Aid for Scientific Research (Fujimoto, No. 00548078) from the Ministry of Education, Science and Culture, Japan. 
(crown-rump (C-R) length, 5-8 mm) and 9 embryos at the 6 th week (C-R length, $11-$ $13 \mathrm{~mm}$ ).

For light microscopic observation, embryos were fixed in $10 \%$ formalin or Carnoy's solution for the colloidal iron reaction and the periodic acid-Schiff (PAS) reaction. After dehydration, they were embedded in paraffin and cut transversely and serially at a thickness of $5 \mu \mathrm{m}$. The sections were stained with PAS by McManus's method (1948) for demonstrating glycogen in the PGCs or by the colloidal iron reaction using Mowry's method (1958) for demonstrating mucins. In the latter case, the sections were first reacted for one hour in the solution with colloidal iron stain, followed by staining for 20 minutes with potassium ferrocyanide. In order to clarify the characteristics of the acid mucin in the PGCs, digestion tests were performed using neuraminidase and hyaluronidase, respectively. High iron diamine (HID) staining was also carried out by Spicer's method (1965) to demonstrate sulfated mucin.

For the alkaline phosphatase (ALPase) reaction, embryos were fixed in 3\% glutaraldehyde, and the appropriate parts (including the hind gut, its dorsal mesentery and gonadal anlage) including PGCs were then excised from the embryos. Thin sections were cut, and immersed in the substrate mixture (final $\mathrm{pH}, 9.0-9.5$ ) according to the lead citrate method of Mayahara et al. (1967). After incubation, some of the sections were embedded in paraffin for light microscopy. Others were post-fixed in 1\% osmium tetroxide, embedded in Epon 812 , and ultrathin sections were cut for electron microscopy. To determine the isozyme pattern of ALPase in the PGCs, the azo-dye method of Burstone (1962) was applied histochemically to serial frozen sections. To investigate the effect of isozyme-specific inhibitors on the ALPase activity, specimens were preincubated in $50 \mathrm{mM}$ of either L-phenylanine or L-homoarginine and/or $10 \mathrm{mM}$ of levamisole for 2 hours at $4^{\circ} \mathrm{C}$. L-phenylalanine or Lhomoarginine at a concentration of 12.5 $\mathrm{mM}$ was further included in the incubation mixture for the enzyme reaction. Heat inactivation of ALPase was also carried out at $60^{\circ} \mathrm{C}$ for 30 minutes, before the reaction.

For general observation by electron microscopy, embryos were prefixed in $3 \%$ glutaraldehyde and the appropriate portions including PGCs (mainly the hind gut region) were excised following post-fixation in $1 \%$ osmium tetroxide. After dehydration, the specimens were embedded in Epon 812. Ultrathin sections were prepared, stained doubly with uranyl acetate and lead citrate, and examined for PGCs under a Hitachi HU-12A transmission electron microscope.

\section{Results}

A. Migration and morphological profile of human PGCs:

Human primordial germ cells (PGCs) are first found morphologically in the yolk sac endoderm of the embryo at the early stage of the 4 th week. They then translocate to the hind gut epithelium, separate from it and eventually migrate into the genital ridge (gonadal anlage) via the dorsal mesentery by the 6 th week of embryonic development (Fig. 1). To illustrate the migration and morphology, ultrastructural profiles of PGCs during the stages of their separation, migration and early settlement are shown in Figures 2, 3 and 4, respectively. The details have been described in our previous reports (Fujimoto et al., 1977, Miyayama et al., 1977).

B. Histochemical findings for human PGCs:

(1) ALPase reaction:

The PGCs located in the hind gut epi- 


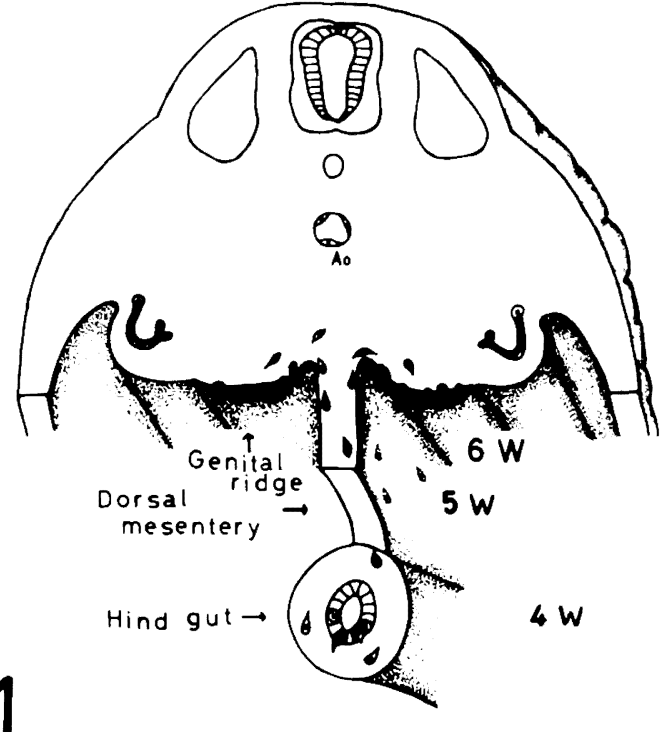

Fig. 1. Semi-schematic drawing of the migration of primordial germ cells (PGCs) from the hind gut to the genital ridge of the human embryo during the 4 th to 6 th week of development.

thelium of the earlier 5 th week embryo were difficult to differentiate from the gut epithelial cells at the light microscopic level, unless the ALPase reaction was used as a means for histochemical identification of the PGCs. By this method, ALPase activity was demonstrated selectively on the surface of the PGC, clearly distinguishing them from the surrounding somatic cells with no enzyme activity at both the light (Fig. 5) and electron microscopic (Fig. 6) levels. Migrating PGCs in tissues (dorsal mesentery or mesenchyme at the coelomic angle) in the 5th week embryo and cells which had arrived at the gonadal anlage in the 6th week embryo, were also clearly differentiated from the neighboring somatic cells by the ALPase reaction which demonstrated the enzyme on the PGC surface. Throughout the extra-gonadal to gonadal stages of PGC migration examined, the PGCs revealed intensive enzyme activity mainly on their plasma membrane at the ultrastructural level (Fig. 6). This ALPase activity was found to be localized pre. dominantly on those parts of the plasma membrane which were closely associated with neighboring cells (Fig. 7). Careful examination revealed the reaction product to be present also in the Golgi apparatus, on the outer membrane of mitochondria, and the nuclear envelope of the PGC (Fig. 8).

Isozyme-specific inhibitors of the ALPase of PGCs were investigated histochemically using serial cryostat sections. L-homoarginine and levamisole specifically inhibited the ALPase activity of PGCs at the light microscopic level (Figs. 9-12). In addition, the enzyme activity was completely abolished by heat inactivation at $60^{\circ} \mathrm{C}$ for 30 minutes. The inhibition tests confirmed that the isozymatic pattern of the ALPase of PGCs was of the liver type.

(2) PAS reaction:

In embryos at the 5 th week, PGCs migrating in the dorsal mesentery or at the coelomic angle were clearly recognized by the PAS reaction as cells with PASpositive granules in their cytoplasm, being of large cell size and having a large nucleus including distinct nuleoli. In embryos at the 4th week, PGCs were embedded in the hind gut epithelium. However, both the PGCs and gut epithelial cells were strongly positive for the PAS reaction, so that some difficulty was encountered in their mutual differentiation by this method.

In embryos at the 6th week, almost all PGCs had arrived at the gonadal primordium. These PGCs were also recognizable by the PAS reaction and were distinct from the neighboring somatic cells without PASpositive granules (Fig. 13), although the PAS-positive granules in the PGCs were decreased in number at this gonadal stage. The PAS-positive material in such PGCs was confirmed to be glycogen. based on 
its complete digestion by $\alpha$-amylase and its morphological appearance as glycogen particles on electron microscopy (see Fig. 2).

\section{(3) Histochemistry of mucins:}

The migrating PGCs in embryos at the 5 th week or those in the primitive gonad at the 6 th week, reacted positively to various stains as follows. The reactions to colloidal iron for acid mucins tended to be localized on the plasma membrane of the PGC (Fig. 14). Also, the reactivity of PGCs for staining of mucoproteins was stronger than that of the surrounding somatic cells, and permitted the PGCs to be distinguished from the somatic cells at the migration and settlement stages. The reaction products were digested by neuraminidase, but not by hyaluronidase treatment (Figs. 15 and 16). HID staining failed to demonstrate sulfated mucin. These findings indicated that the acid mucin on the plasma membrane of the PGC included sialic acid, but neither hyaluronic nor sulfated mucins.

\section{Discussion}

It has been generally accepted on the basis of previous studies (Mckay, 1953, Jeon and Kennedy, 1973, Clark and Eddy, 1975, Eddy and Clark, 1975, Fujimoto et al., 1977) that ALPase activity is fundamentally and characteristically demonstrated on the plasma membrane of PGCs in mammals. In the present study, some enzyme activities were also observed on the membranes of the Golgi apparatus, mitochondria and nuclear envelope as well as the plasma membrane of the PGC. Similar results have been reported for mouse PGCs (Jeon and Kennedy, 1973). In addition, it was interestingly found in the present study that the ALPase activity was localized predominantly on parts of the plasma membrane where the PGCs were mutually con- nected or closely associated with neighboring somatic cells. Recently, Swartz (1982) obtained similar findings for chick PGCs at the active phase of migration, where ALPase activity was demonstrated intensively on those parts of the plasma membrane which were associated with neighboring somatic cells. Although the precise role of ALPase in PGC function or in PGC migration remains undetermined, the above findings suggest some interaction at least between the PGCs and neighboring somatic cells. They may be involved partly in gas and metabolic exchanges, or may participate in some way through the differential localization of the isozymatic characteristics of ALPase in PGCs.

It is well known that, in humans, there are at least three gene loci which determine the different forms of ALPase. One locus codes for the term placental form, one for the intestinal form, and one for the liver/bone/kidney forms (McKenna et al., 1979, Seargeant and Stinson, 1979, Goldstein, 1980). These isozymes can be readily distinguished from one another by biochemical, immunological and cytochemical procedures (Fishman, 1974). In the present study, the ALPase on the PGCs was found to be of the liver type from the isozymatic standpoint. Additional studies are required to clarify the significance of this finding and the location sites associated with the isozyme.

Glycoprotein is an essential component of the membrane structure of cells (Lehninger, 1968, Siger and Nicolson, 1972). In order to characterize the PGCs of human embryos, therefore, we undertook colloidal iron staining for acid mucin as a new means of identifying and establishing the histochemical characteristics of PGCs. Except the early stage, PGCs examined in stages from the gut to gonad were positive for the staining of acid mucin and 
clearly distinct from other somatic cells. The reaction product was located mainly on the plasma membrane. In addition, it was confirmed by mucin histochemistry that the acid mucin on the plasma membrane of PGCs included sialic acid, but neither hyaluronic nor sulfuric acid.

The PAS technique as well as mucin histochemistry was effective for identifying PGCs in the migration and settlement stages. The PAS reactivity of PGCs corresponds to the glycogen content of the cells, as mentioned in our earlier reports. They become progressively deprived of cytoplasmic glycogen, with extreme diminishment in later gonadal PGCs. This might coincide with the stage at which the PGCs take a step towards further differentiation to germ cells, as pointed out previously (Fuyuta et al., 1974, Fujimoto et al., 1977), or obtain the energy source for their migratory ability as one of the most prominent characteristics of PGCs (Clawson and Domm, 1963, Fujimoto et al., 1977).

The present study thus demonstrates the histochemical characteristics of human PGCs in combination with histochemical identification of the cells. In addition, ultrastructural profiles of PGCs are also given.

\section{References}

1) Burstone, M. S.: Enzyme histochemistry and its application in the study of neoplasms. Academic Press, New York, 1962.

2) Clark, J. M. and Eddy, E. M.: Fine structural observation on the origin and associations of primordial germ cells of the mouse. Devel. Biol., 47: 136-155, 1975.

3) Clawson, R. C. and Domm, L. V.: Developmental changes in glycogen content of primordial germ cells in chick embryos. Proc. Soc. Exp. Biol., 112: 533-537, 1963.

4) Eddy, E. M. and Clark J. M.: Electron microscopic study of migrating primordial germ cells in the rat. In "Electron microscopic concepts of secretion." The ultrastructure of endocrine and reproductive organs. 151168, Wiley, New York, 1975.

5) Fishman, W. H.: Perspectives on alkaline phosphatase isoenzyme. Am. J. Med., 56 : 617-650, 1974.

6) Fujimoto, T., Miyayama, Y. and Fuyu1a, M.: The origin, migration and fine morphology of human primordial germ cells. Anat. Rec., 188: 315-330, 1977.

7) Fuyuta, M., Miyayama, Y. and Fujimoto, T.: Histochemical identification of primordial germ cells in human embryo by PAS reaction. Okajimas Folia Anat. Jpn., 51: 251-262, 1974.

8) Goldstein, D. J., Rogers, C. E. and Harris, H.: Expression of alkaline phosphatase loci in mammalian tissues. Proc. Nat. Acad. Sci., 77: 2857-2860, 1980.

9) Jeon, K. W. and Kennedy, J. R.: The primordial germ cells in early mouse embryo: Light and electron microscopic studies. Devel. Biol., 31: 275-283, 1973.

10) Lehninger, A. L.: The neuronal membrane. Proc. Nat. Acad. Sci., 60: 1069-1080, 1968.

11) Mayahara, H., Hirano, H., Saito, T. and Ogawa, K.: The new lead citrate method for the ultracytochemical demonstration of activity of non-specific alkaline phosphatase. Histochem., 11: 88-96, 1967.

12) McKay, D. G., Herteig, A. T., Adams, E. C. and Dazinger, S.: Histochemical observations on the germ cells of human embryos. Anat. Rec., 117: 201-220, 1953.

13) McKenna, M. J., Hamilton, T. A. and Sussman. H. H.: Comparison of human alkaline phosphatase isoenzyme. Structural evidence for three protein classes. Biochem. J., 181 : 67-73. 1979.

14) McManus, F. A.: Histological and histochemical uses of periodic acid. Stain Techn.. 23: 99-108, 1948.

15) Miyayama, Y., Fuyuta, M. and Fujimoto, T.: Ultrastructural observations on the origin, amoeboid features and associations of human primordial germ cells. Acta Anat. Nipponica. 52: 255-268. 1977 (in Japanese).

16) Mowry, R. W.: Improved procedure for the staining of acidic polysaccharides by Muller's colloidal (hydrous) ferric oxide and its combination with the Feulgen and the periodic acidSciff reaction. Lab. Invest.. 7 : 566-576, 1958.

17) Seargeant, L. E. and Stinson, R. A.: I vidence that three structural genes code for human alkaline phosphatases. Nature, 281 : 152-154, 
1979.

18) Singer, S. J. and Nicolson, G. J.: The fluid mosaic model of the structure of cell membranes. Science, 175: 720-731, 1972.

19) Spicer, S. S.: Diamine methods for differentiating mucopolysaccharides histochemi- cally. J. Histochem. Cytochem., 13: 211-234, 1965.

20) Swartz, W. J.: Acid and alkaline phosphatase activity in migrating primordial germ cells of the early chick embryo. Anat. Rec., 202: 379-385, 1982. 


\section{PLATES}




\section{Explanation of Figures}

\section{Plate I}

Fig. 2. Electron micrograph of a PGC separting from the hind gut epitherlium into the outer mesenchyme of a human embryo with 22 -somites at the 4 th week.

The PGC protrudes a cytoplasmic process through the breakage (arrow) in the basal lamina.

HG: hind gut epithelium, L: lumen of the hind gut, GL: accumulation of glycogen particles, Lp: lipid droplet. 


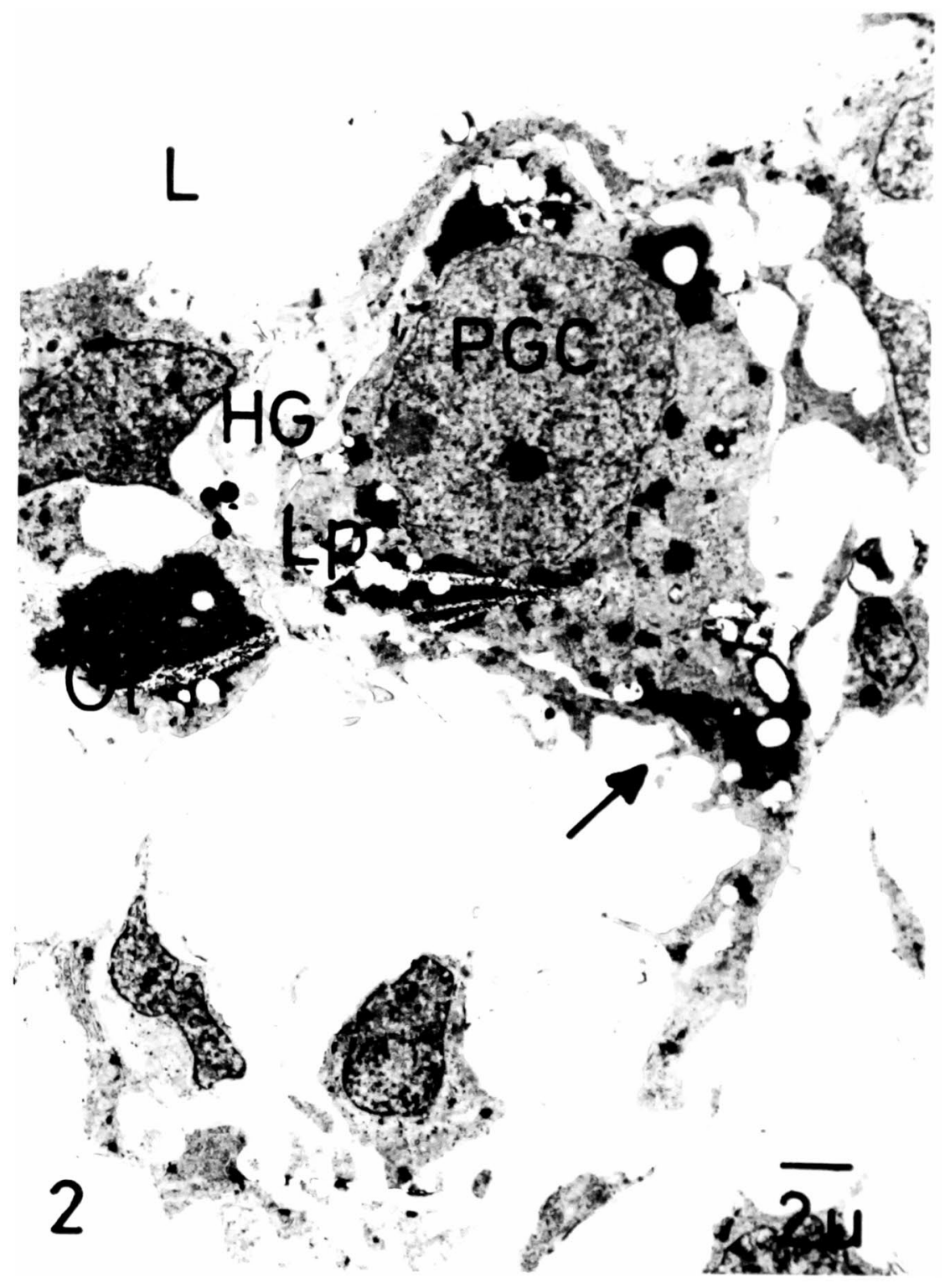




\section{Plate II}

Fig. 3. Electron micrograph of a migrating PGC in the dorsal mesentery of a 5 th week human embryo (crown-rump (C-R) length, $6 \mathrm{~mm}$ ).

The PGC is elongated by extending irregular cytoplasmic processes showing amoeboid features. $\times 3,000$

Fig. 4. Electron micrograph of PGCs accumulated near or in the genital ridge (Gr) in a 5 th week human embryo (C-R length, $7 \mathrm{~mm}$ ).

One PGC (lower right) appears to have just arrived at the genital ridge, while another (upper left, arrowed) still appears to be migrating towards the genital ridge. $\times 1,800$ 

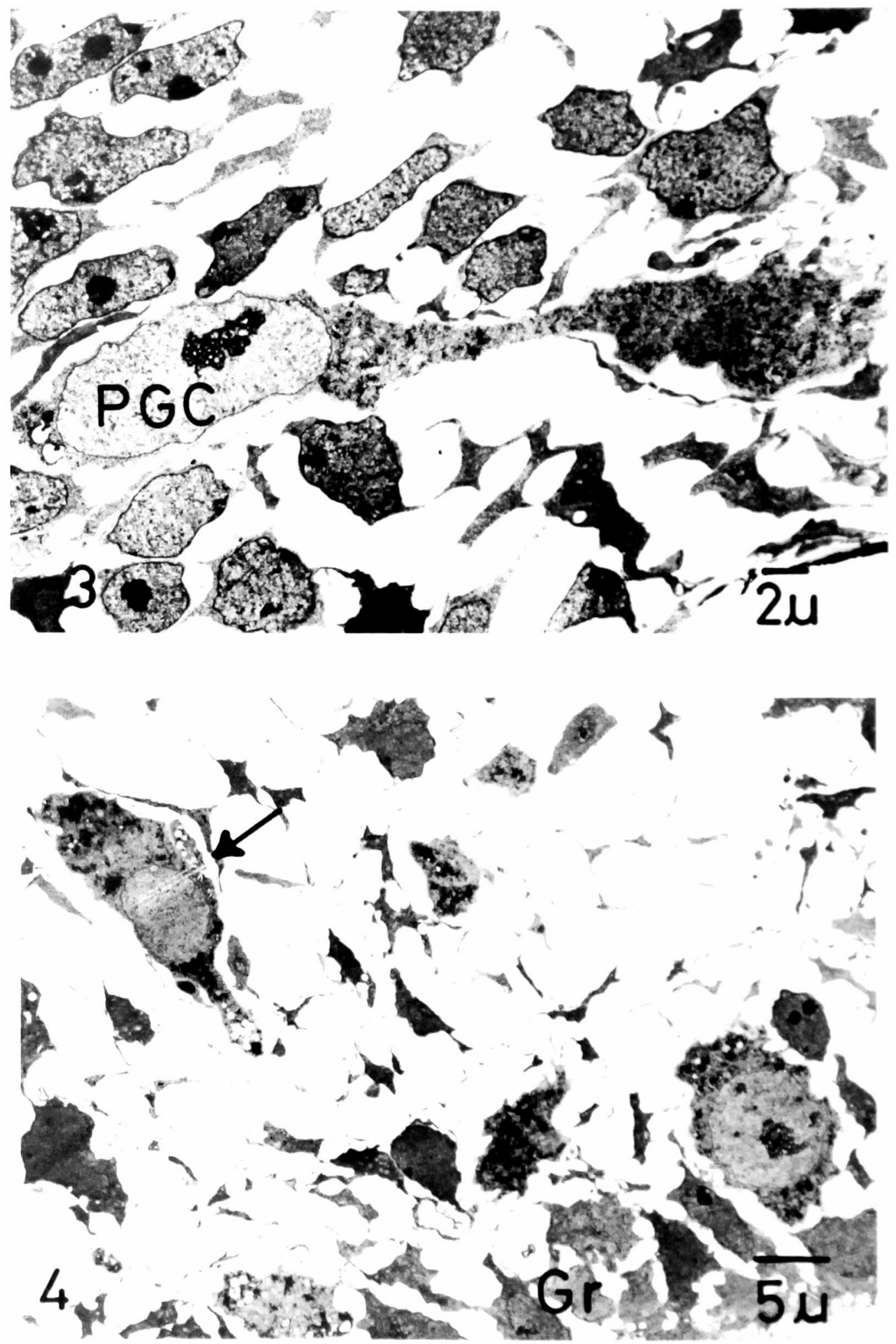


\section{Plate III}

Fig. 5. Transverse paraffin section of the hind gut of a 5 th week human embryo (C-R length, $5 \mathrm{~mm}$ ) subjected to the ALPase reaction.

PGCs embedded in the hind gut (HG) epithelium are clearly identified by the intensive enzyme reaction on their surfaces (arrows). $\times 500$

Fig. 6. Electron micrograph of the hind gut of a 5 th week human embryo (C-R length, $5 \mathrm{~mm}$ ) subjected to the cytochemical ALPase reaction to differentiate the PGCs from the gut epithelium cells.

The enzyme activity is confirmed to be localized on the plasma membrane of the PGC. $\times 7,000$ 

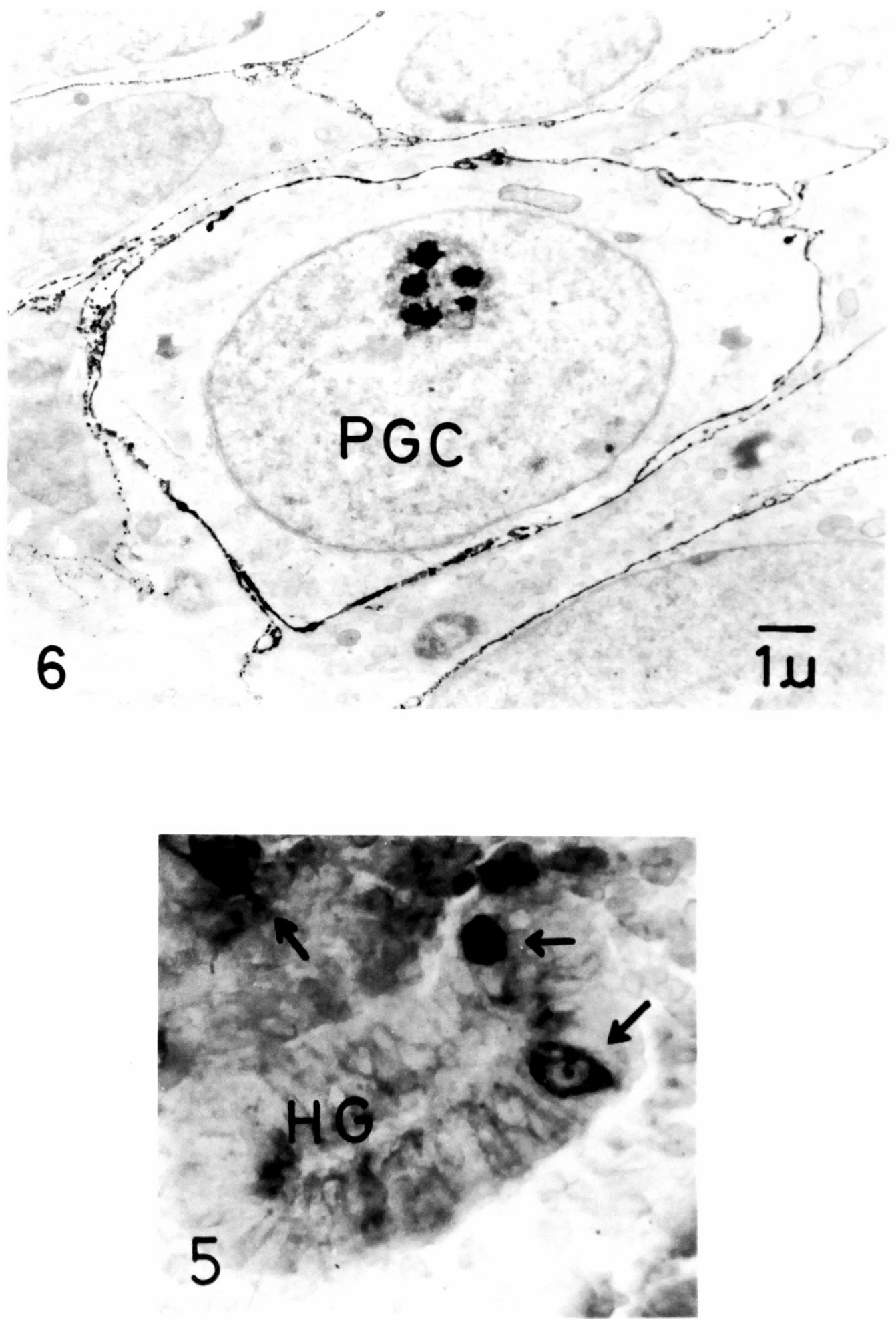


\section{Plate IV}

Fig. 7. Electron micrograph of a migrating PGC in the dorsal mesentery of a 5 th week human embryo (C-R length, $6 \mathrm{~mm}$ ) subjected to the ALPase reaction.

The reaction product for the enzyme activity of the PGC is localized on the plasma membrane, which is closely associated with the adjoining somatic cells (arrow). $\times 4,800$

Fig. 8. Electron micrograph of a PGC in the primitive gonad of a 5 th week human embryo (C-R length, $8 \mathrm{~mm}$ ) subjected to the ALPase reaction.

An intracytoplasmic reaction is observed in the Golgi apparatus (G) and on the outer membrane of mitochondria (M). ER : endoplasmic reticulum. $\times 20,000$ 


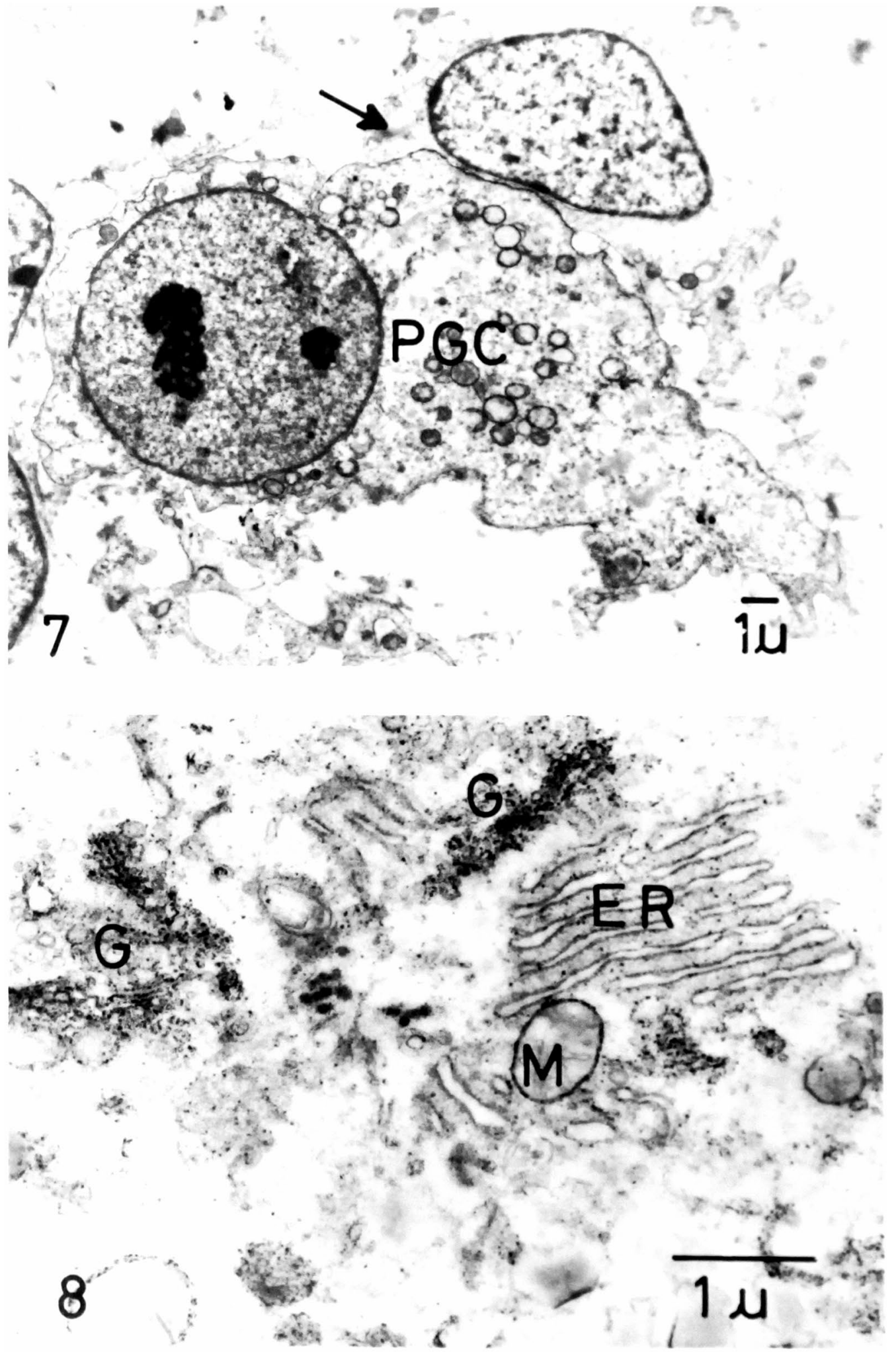




\section{Plate V}

Figs. 9-12. Isozymatic pattern for the ALPase of PGCs in a 6th week human embryo (C-R length, 11-13 $\mathrm{mm}$ ) stained for histochemical inhibition tests.

Fig. 9. Regular reaction: PGCs in the primitive gonad show an intense reaction. $\times 450$

Fig. 10. L-phynylalanine treatment: the enzyme activity of the PGCs in the primitive gonad is not inhibited by the treatment. $\times 250$

Fig. 11. Levamisole treatment: the enzyme activity of the PGCs in the primitive gonad is completely inhibited by the treatment. $\times 150$

Fig. 12. Heat inactivation: the enzyme activity is heat-labile and completely abolished by treatment at $60^{\circ} \mathrm{C}$ for 30 minutes. $\times 150$ 


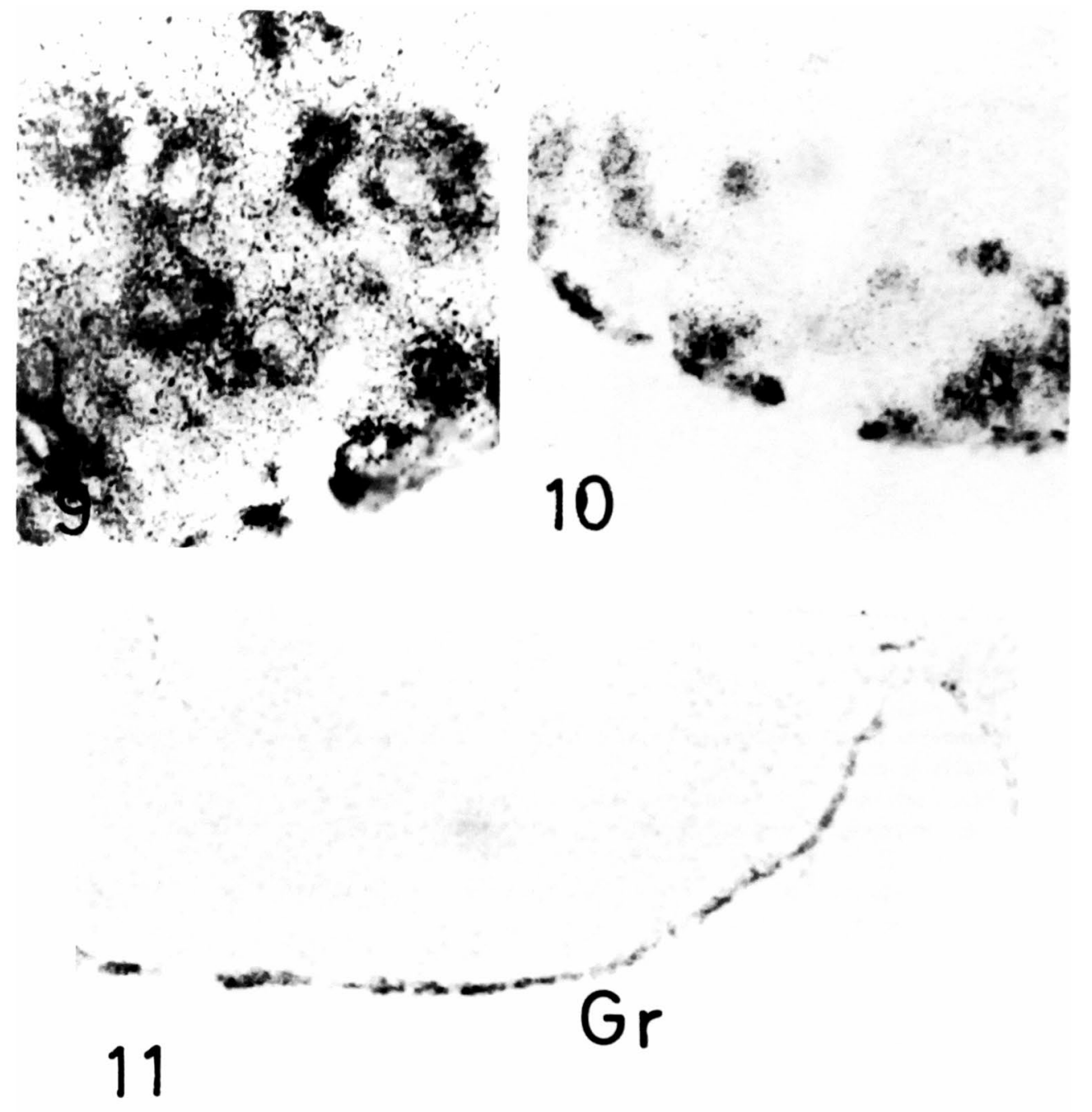

$\mathrm{Mt}$ 


\section{Plate IV}

Fig. 13. Transverse paraffin section of the primitive gonad of a 6 th week human embryo (C-R length, 12.5 $\mathrm{mm}$ ) stained for the PAS reaction.

PGCs are recognized in the primitive gonad by their strong PAS reactivity and are clearly distinguishable from the somatic cells. $\times 400$

Fig. 14. Transverse paraffin section of a 6 th week human embryo (C-R length, $12 \mathrm{~mm}$ ) stained for the colloidal iron reaction.

The PGCs situated in the primitive gonad are recognized by their colloidal iron reaction (arrows). The reaction products tend to be localized on the plasma membrane of the PGCs. $\times 650$

Figs. 15 and 16. Digestion tests for the acid mucin of PGCs in the primitive gonad of a 6 th week human embryo (C-R length, $11-13 \mathrm{~mm}$ ).

Fig. 15. The reaction products in the PGCs are completely digested by neuraminidase treatment. $\times 400$

Fig. 16. The reaction products on the plasma membrane of the PGCs are not digested by hyaluronidase treatment. $\times 400$ 

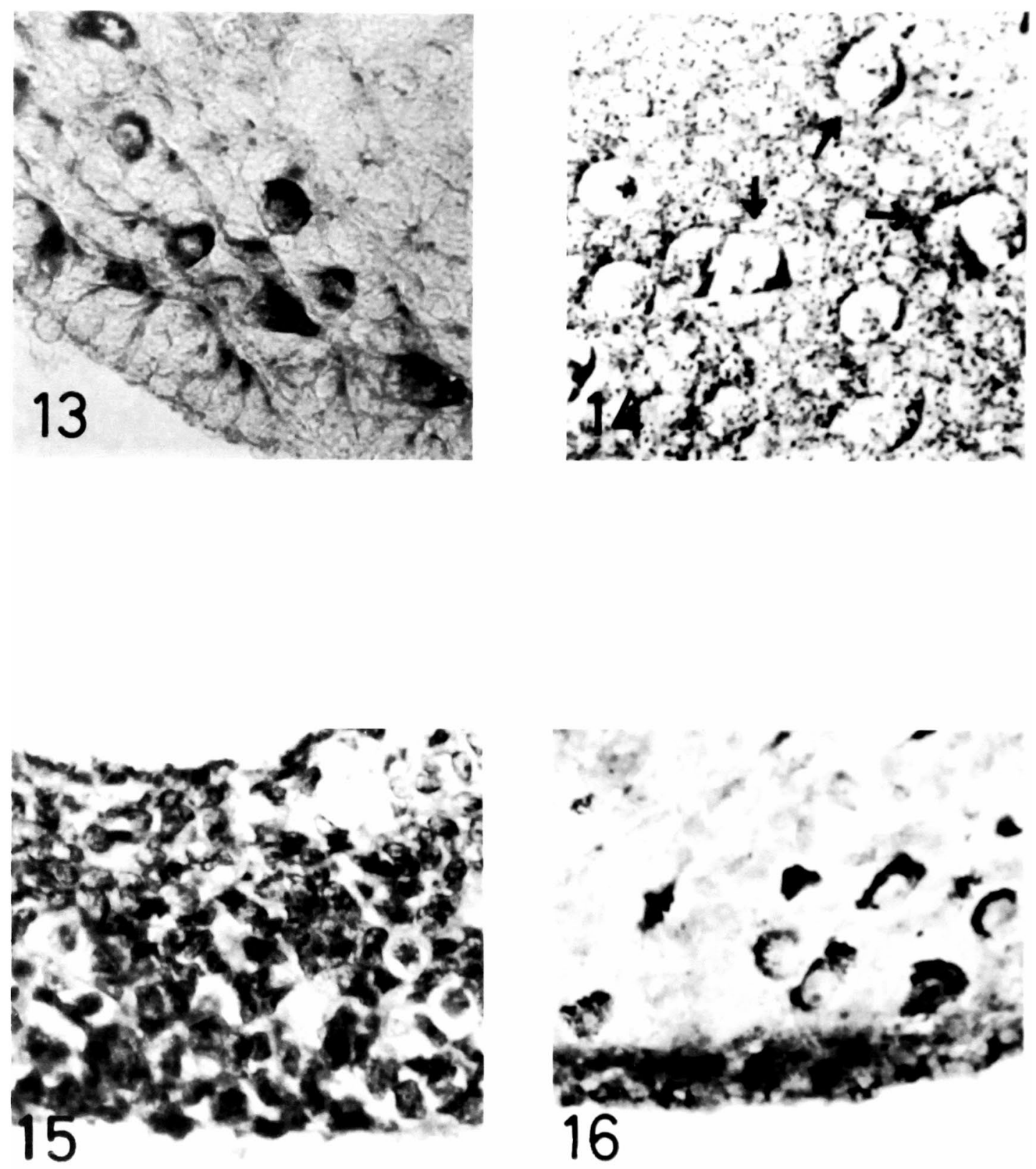